\title{
19
}

\section{COLLECTIVE REASONING IN ELEMENTARY ENGINEERING EDUCATION}

\author{
Christine M. Cunningham and Gregory J. Kelly
}

\section{Summary}

Properly designed engineering curricula can engage students in the engineering design process to foster creativity, problem solving, and communicative competence. This chapter examines how curricula can be designed to provide learning opportunities for students as they propose, communicate, modify, and evaluate multiple solutions within and across small group and whole class conversations to optimize their engineering designs. By making the criteria and constraints, prototypes, and proposed solutions available for public scrutiny, students can hold themselves and each other accountable across discourse events in classrooms. In the illustrative case of elementary engineering presented in this chapter, students analyze data collected by themselves and classmates and use the results to make evidence-based decisions about engineering solutions in an iterative engineering design process.

\section{Introduction}

Humans in modern society spend $98 \%$ of our time interacting with the humanmade, or engineered, world. For example, we use toothpaste, bicycles, bandages, stairs, and smartphones. Traditionally, school has primarily included study of the natural world through science. Recently, however, in the United States, engineering has become part of K-12 science education; the Next Generation Science Standards (NGSS Lead States, 2013) and many state standards now include engineering. The discipline of engineering offers interesting possibilities for engaging students in ill-structured problems set in social contexts that differ from science. These stem in part from the purposes of the two disciplines (Cunningham \& Carlsen, 2014). Science aims to describe, understand, and predict the natural 
world. Ultimately its goal is to articulate encompassing theories or descriptions. Engineering aims to create technologies (objects, systems, or processes) that solve problems (Cunningham, 2018). It strives to optimize solutions given certain resources and constraints. These possible solutions to a problem can be numerous and varied and depend on the client, the situation, and the criteria and constraints multiple satisfactory outcomes can exist. For example, the best design for a bridge crossing a small stream in rural Pennsylvania is quite different than that which spans San Francisco Bay. People wear different types of footwear depending on what they are doing (dancing at a party, hiking up a mountain, relaxing in the park), the shape and needs of their feet, and their personal preferences. The openended nature of engineering offers possibilities in classrooms for stimulating new opportunities for students to think and reason. Instead of working toward a singular answer, students should consider and evaluate a number of designs.

Because engineering is a fairly new subject in K-12 classrooms, there is a need to create activities, challenges, and curricula for this area. As we do so, it is important to think about how to represent engineering concepts and practices in an age-appropriate manner. To ensure that all children can participate and learn, engineering materials should be developed so they include all students (Cunningham \& Lachapelle, 2014) and provide scaffolds so students are learning from and with each other. Fifteen years ago, one of the authors (Cunningham) founded the Engineering is Elementary (EiE) program to tackle the challenge of creating engineering curricula for all children. She and her team created three school-based engineering curricula for the preschool, kindergarten, and elementary levels as well as two for afterschool and summer camp settingsone for the elementary and one for the middle school level. Overall, the team created 69 award-winning engineering units for preK-8. These are rooted in a theory of learning that situates students in social contexts where disciplinary knowledge is constructed in the service of solving problems (Hutchins 1995; Kozulin 2003; Vygotsky, 1978). This view of learning suggests that students need opportunities to engage in purposeful activity to develop conceptual understanding through discourse processes (reading, writing, speaking) (see Kelly, McDonald, \& Wickman, 2012; Reveles, Kelly, \& Durán, 2007). As we as developers created materials, we thought deeply about how to design engineering challenges and instructional supports that would engage students in authentic tasks and foster problem solving, innovation, and critical thinking. This led us to articulate and refine design principles for the development of engineering activities (Cunningham, 2018; Cunningham \& Lachapelle, 2014; Lachapelle \& Cunningham, 2014). Overall, three sets of frameworks to anchor the creation of the engineering curricular materials were developed.

\section{Conceptual frameworks}

A mission to include and retain all students, particularly those students traditionally underserved or underrepresented in STEM disciplines, led Cunningham 
to articulate a set of 14 inclusive design principles (Cunningham \& Lachapelle, 2014; Cunningham, 2018). For example, engineering challenges should be set in a narrative context that highlights how engineering can help people, animals, society, or the environment; should assume no previously familiarity with materials, tasks, and terminology; and should develop challenges that require lowcost, readily available materials.

Fifteen years ago when we began this work, engineering for elementary-aged students was a radical idea. We asked ourselves what high-quality engineering would look like in the classroom. We also read studies of engineering work in professional settings (Bucciarelli, 1994; Johnson, 2009; Petroski, 2006; Vincenti, 1990). From these, we distilled a set of 16 practices of engineering (Cunningham \& Kelly, 2017a). For instance, these include: envisioning multiple solutions, making tradeoffs between criteria and constraints, making evidence-based decisions, and communicating effectively. We considered what age-appropriate manifestations of these might be.

\section{Development processes and cycles}

Creating curricular materials that were innovative but that worked with the realities of classrooms today was also a guidepost of the project. To develop high-quality materials, the EiE team followed an iterative process of development. Critical to this was close collaboration with practicing classroom teachers as advisors and as field testers of the materials. Hundreds of teachers provided feedback about the lessons and materials to ensure that conceptual bases were translated into the realities of classroom life. The development process has allowed the program to scale-EiE materials have reached over 20 million children and 200,000 educators.

\section{Systems approach}

Finally, the work recognized the interdependence of three domains: curriculum, professional development, and evaluation and research. As we developed resources, we considered how these areas mutually support one another and developed all domains in tandem.

This chapter examines how carefully designed curricular units can provide opportunities to learn disciplinary knowledge in engineering and science. By considering these opportunities in detail, we document the ways that engaging students in the engineering design process (EDP) (Figure 19.1) fosters creativity, problem solving, and communicative competence, while adhering to the constraints of recognized knowledge in the fields of engineering and science. This paper explores how engineering challenges and instructional supports can be designed to support students in this kind of work. To illustrate what this looks like in an elementary classroom, we draw from one representative curricular unit of the EiE curriculum. 


\section{The Engineering Design Process}

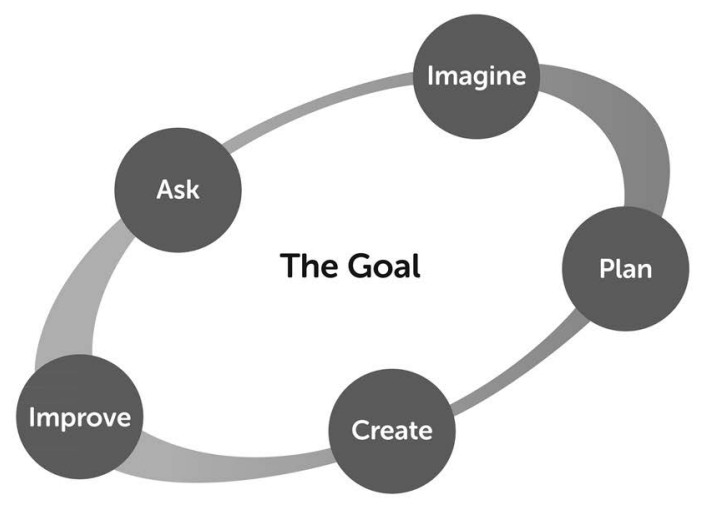

FIGURE 19.1 EiE's elementary engineering design process.

\section{Description of the method}

In this section, we explore some principles that underlie the development of engineering challenges that support creativity, problem solving, and communicative competence in children. Overall, the strategies focus on engaging students in purposeful activity, asking them to draw from current and constructed knowledge to develop solutions, and providing a social basis for the evaluation of the solution by inviting them to share the evidence they collected and analyzed within their student group and with the larger class. To illustrate what this looks like, we offer examples from one EiE unit, Lighten Up: Designing Lighting Systems (EiE, 2011a). This unit introduces students to optical engineering by having them explore how to use their science knowledge related to the properties of light (reflection, refraction, and intensity) as they design a lighting system using a flashlight and mirrors to illuminate hieroglyphics on the inside of a model Egyptian tomb.

\section{Provide a context}

Children are more motivated when they can situate what they are learning in the real world (Hmelo-Silver, 2004). We believe engineering challenges should begin with a context that helps students to understand why the work they will undertake matters and, hopefully, motivates them to tackle the challenge. Connecting classroom activities to the real world through a narrative can help children see it as relevant. There are many ways to do this; the media and method will vary. For example, we use a puppet to introduce challenges for preschoolers, illustrated storybooks kick-off units for elementary students, and short videos 
highlight how professional engineers are solving the same problems as middle school students. In each of these media, connections are made to topics of potential interest for the students. In the example below, we describe how optical engineering ties to tombs in Egypt.

In the first lesson of the Lighten Up unit students read a storybook, Omar's Time to Shine (EiE, 2011b). In the book, Omar, a boy in Egypt, is involved in a school dance performance. His brother, an optical engineer, works at the Valley of the Tombs in Egypt. While visiting him, Omar learns about how a system of mirrors had been used many years ago to reflect the sun's rays and illuminate the artwork deep inside the chambers. Omar puts this knowledge to use when a brownout occurs during his dance performance. He uses the engineering design process and what he knows about light and optical engineering to save the show. After they read the book, students in the class tackle a similar challenge.

\section{Scaffold the problem-solving process}

One core engineering concept is the use of a structured engineering design process. This systematic and iterative process guides the development of new technologies. To help students move beyond tinkering and to orient students to the goal of the activity at hand, an explicit engineering design process is valuable. We created an age-appropriate, five-step process for elementary students (Ask Imagine - Plan - Create - Improve) (Figure 19.1), a three-step process for preschoolers, and an eight-step process for middle schoolers. But regardless of the number of steps, what is important is that the process focuses students' work so they are engaging in reflective problem-solving, not just doing crafts or following a set of steps. The process should ask them to think and plan, reflect and evaluate their designs against a goal, and use what they learn to improve their technology. This goal-directed activity allows students to apply creativity to their solutions, while holding such solution accounts to a public standard of success.

Our engineering design process (EDP), centers around a goal. For the Lighten Up unit, the goal is "to design a lighting system for a tomb that lights up as many hieroglyphs as possible with the greatest possible intensity" (EiE, 2011a, p. 119). The "hieroglyphics" (an image of a vulture) are taped on six locations on the inside walls of a copy paper box. Using a flashlight that they shine through an opening in the wall, the students design ways to position mirrors that reflect the light to illuminate the vultures. Figure 19.2 is a photograph of students building their lighting system in the box. A mirror in the lower left is held by a student. Images of the vulture ("hieroglyphics") are taped on the walls at specified locations (a constraint on the system). Notice the students are coordinating across the modes of representation - their notebook sketch on the left and the grid of the box ("tomb").

Our five-step engineering design process devotes three of the steps to work that is often done before students begin physical construction. Professional 


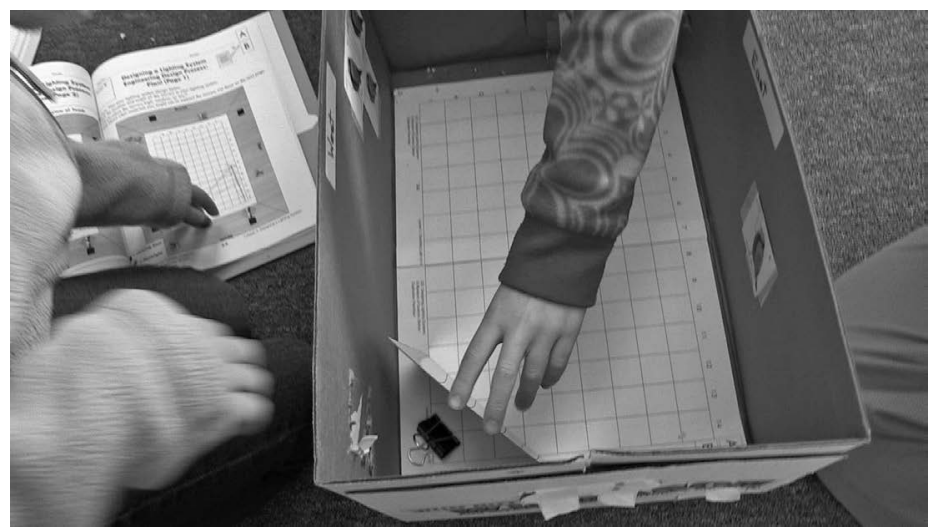

FIGURE 19.2 Students working on the optimal engineering design challenge.

engineers usually create detailed plans, backed by knowledge, tests, and data, before the actual building of a technology (such as an airplane or auditorium) begins. Students, too, should recognize that activities such as identifying the question, drawing on previous knowledge, brainstorming possible solutions, considering materials and other constraints and criteria, and creating a detailed plan are important work for engineers. These problem-solving strategies, while contextualized to this challenge, can also be generalized and applied to other situations. The technologies students construct will be better if they spend some time learning and thinking about them.

For some students, the task of engineering a solution might initially seem daunting. Outlining a process, with steps that each have questions that guide students' work for that day, can make the work much more approachable. For example, when students are engaged in the "Ask" phase, they are prompted to consider: What's the problem? What have others done? What are the constraints? (EiE, 2011a, p. 4-1).

\section{Articulate criteria and constraints}

Optimizing a design entails understanding the limitations and specifications that the design must meet. Challenges should articulate these criteria (requirements of the design) and constraints (limits that restrict the design such as materials, cost, or space) early in the process. Students and professional engineers create better designs if they understand what their guidelines are. Working with students to develop a list, posted at the front of the classroom, that outlines the challenge's criteria and constraints creates a public record for review throughout the design and testing processes. Some of the criteria and constraints will likely be clear at the outset of a challenge; others might arise during an activity and can be added. Students will need to balance the tradeoffs between these as they optimize their solutions. 
One consideration in creating engineering challenges for young students is that they are challenging but not overwhelming. Students should be able to reach the criteria eventually but not immediately. The parameters for success should leave room for improvement as they motivate students to improve their technologies. And, as the next section discusses, they should afford a range of possible designs. In large part, these variables depend on the criteria and constraints of the challenge. To establish ones that are reasonable for and attainable to students, curriculum development teams should test many, many possibilities to inform the final choices.

In the optical engineering unit, the students engage in a lesson designed to help them learn more about the properties of light and the criteria and constraints of the challenge at hand. Based on the activities they have done in science class and a set of activities designed to help them see that light travels in straight lines and can be reflected, students generate a "What We Know About Light" list. Through their investigations they conclude:

- $\quad$ Light travels in a straight line until it hits another object.

- Light can be absorbed.

- Light can be reflected.

- The angle of incidence is always equal to the angle of reflection.

- The shorter the distance from a light source, the more intense the light.

- The greater the distance form a light source, the less intense the light. (EiE, 2011a, p. 111)

In this case, some of the properties of light also serve as constraints, and in this manner students learn science (properties of light) through the investigations. Additionally, the students work with their teachers to construct a list of the criteria and constraints for this challenge (see Figure 19.3). The teacher provides

\begin{tabular}{|c|c|}
\hline \multicolumn{2}{|c|}{ Criteria and Constraints for our Lighting System } \\
\hline Criteria & Constraints \\
\hline $\begin{array}{l}\text { - You need to light up as many of } \\
\text { the hieroglyphs as possible. } \\
\text { Intensity } \\
\text { - The light shining on the } \\
\text { hieroglyphs should be as } \\
\text { intense as possible so that the } \\
\text { artists can see enough details } \\
\text { to copy them accurately. }\end{array}$ & $\begin{array}{l}\text { - There is only one light source } \\
\text { in the southeast corner of } \\
\text { the tomb and it cannot be } \\
\text { moved. } \\
\text { - The tomb cannot be } \\
\text { changed_-you can't change } \\
\text { its size or cut openings into } \\
\text { it. } \\
\text { - The hieroglyphs cannot be } \\
\text { moved. } \\
\text { - Cost should be low. }\end{array}$ \\
\hline
\end{tabular}

(EiE, 2011a, p. 112)

FIGURE 19.3 Criteria and constraints for the lighting systems generated by students. 
a "price sheet" for the components that the students have access to when they create their designs (different sized mirrors, index cards, craft sticks, tape). The teacher also demonstrates the method the class will use to measure the intensity of the light that reaches each of the six hieroglyphics the students are trying to illuminate. The students need to balance multiple variables - it is complicated, so they gather data and create records that document how to achieve solutions within the given constraints.

\section{Structure activities with multiple solutions}

Engineering problems in the real world are open-ended - there are many ways to solve them and engineers continually develop new solutions. In the classroom, too, students should engage in challenges that afford multiple possible solutions. The opportunity to design a solution that is unique is something that is highly motivating to students, as it allows them to apply their own creativity and insight. As mentioned above, in designing or selecting engineering challenges, reviewing whether they encourage a diversity of solutions is an important consideration.

One way to encourage a range of ideas is to provide students with a number of different kinds of materials. In the lighting challenge, students have mirrors of two sizes to choose from. They will need to figure out how many mirrors they will use and where and how in the box to position them. The angle of reflection is one variable they will consider. But they also will consider how to mount the mirrors. Index cards, craft sticks, binder clips, string, tape, and pipe cleaners are available. Students design how they will prop, hang, or adhere the mirrors, and at which heights within the box. Encouraging students to exercise their creativity often results in novel solutions. Some of their solutions will work well and some will not - those that do not may prompt another innovative approach.

\section{Develop students' shared knowledge, experiences, and resources}

Professional engineering teams have shared knowledge that grounds their conversations and decisions. Such common understandings permit deeper, more probing interactions (Cunningham \& Kelly, 2017b). To allow students to engage in meaningful discussions that push ideas in new but relevant directions, engineering experiences should establish common understandings and protocols that students can reference. It permits students to ask much more insightful questions of their team and class members. And it opens up possibilities for cross-pollination of ideas that are rooted in knowledge. Including time for all members of the class to engage in common experiences and sense making ensures that all class members benefit from such knowledge and enter the challenge on a more equal footing, thus potentially alleviating some of the disparities that might exist between students with respect to their previous access to related resources and activities. 
Starting with a defined set of materials for an engineering challenge can allow students to gain familiarity with them, their properties, and how they function. Before students start thinking about how to use the materials to solve a problem, they should explore them. They should touch and manipulate them, learn their names, and conduct scientific tests that build their understanding of which might work best to meet certain challenges. Because the types of materials are limited and common to all students (each group does not use different materials), all students develop familiarity and have experiences with them. Thus, they can engage in conversations and questioning across groups. This helps build up the students' repertoire of technical terms, labels for engineering processes, and descriptions of possible solutions.

For example, before students begin brainstorming possible designs for their lighting system, they investigate the mirrors they will use. They undertake a series of experiments designed to help them understand how mirrors work. They learn, through exploration and class conversation, what reflection, refraction, angle of incidence, and intensity are. Through these shared experiences, students develop shared understandings and a common language.

The engineering design experiences also introduce and hold students accountable to common rubrics, data tables, and testing protocols. These are set out in worksheets and students review them as a class to understand what to do and how to do it. This allows students to share and reason as a group and as a class. Students in the Lighten Up unit use additional shared resources as they begin the challenge. A common protocol for calculating the cost of their solution and a class protocol for measuring the intensity of the light, allow students to share their ideas and results. Figure 19.4 shows the worksheet that students will complete to assess their lighting system design solutions. During the Create phase of the engineering design process students build their solution for lighting the hieroglyphic images, while trying to optimize the light intensity (criteria) and minimizing the costs (constraints)—see Figures 19.2 and 19.3. The scoring process is tabulated on the form presented in Figure 19.4. In this case, the students are able to calculate the total score of the engineering design by using quantifiable measures of costs and light intensity. These are important considerations in engineering-while there can be multiple solutions, and creativity is encouraged, any given solution is held accountable to imposed criteria and constraints. This common forum for calculating ways to optimize proposed solutions allows students to compare across groups and learn from each other.

\section{Make data and discussions a shared resource}

As mentioned above, one of the principal reasons for fostering shared experiences, using shared procedures, and reporting mechanisms is that students can learn with and from each other. A critical part of such interactions is having students share the results of their work and what they have learned with each other. This allows students the opportunity to engage in discourse practices relevant 
Name:

Date:

Design \#

\section{Designing a Lighting System Engineering Design Process: Create!}

Directions: Complete the chart below with each of the scores for your lighting system design. Add all of your scores together to get your Total Score.

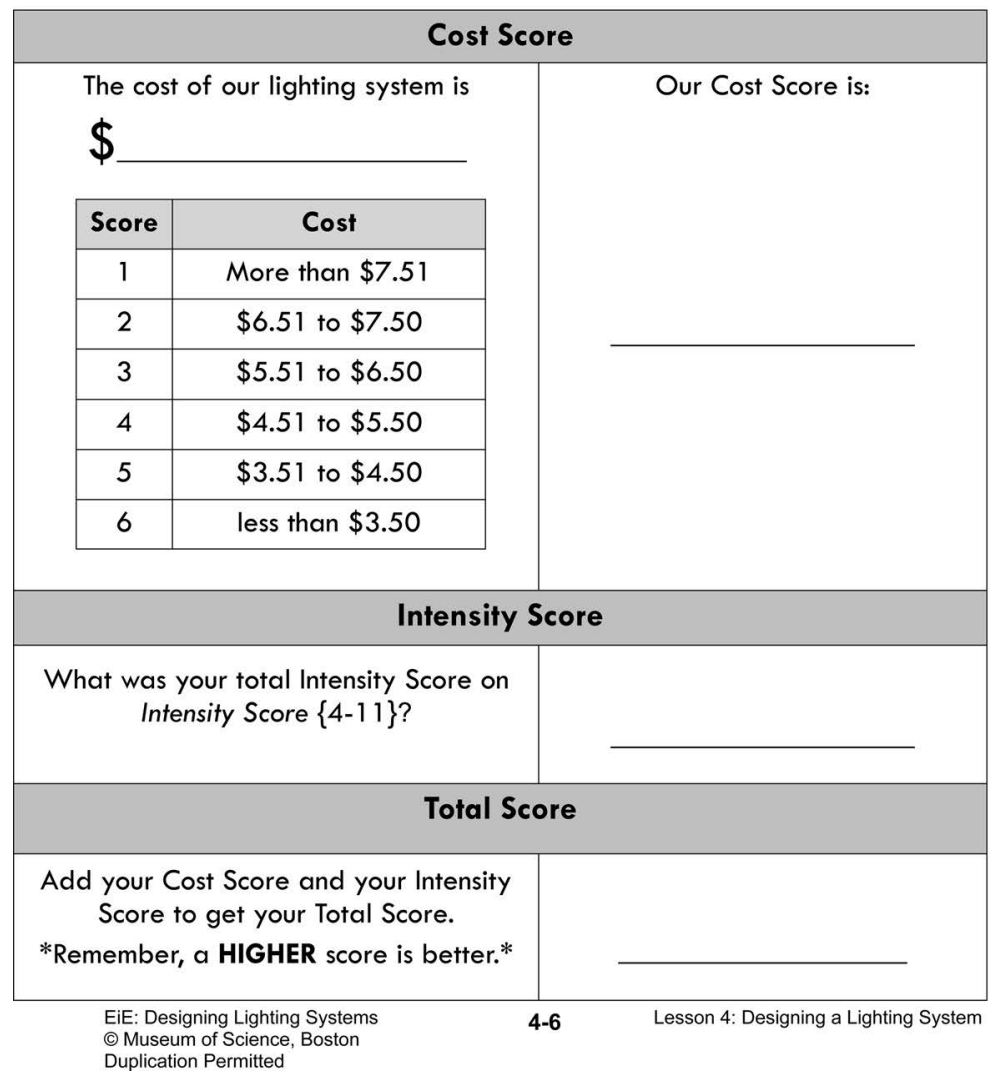

FIGURE 19.4 Student worksheet for assessing design solutions.

to learning the disciplinary knowledge (Kelly, 2016). They learn by articulating their views and listening to others.

Using common materials, engaging in common protocols for testing, gathering similar data, and reporting it in similar forms, enables students to pool their data, analyses, and reflections. In some classrooms, students engage in public testing of their designs - classmates watch the testing of the technologies. By observing the performance of their and others' designs, students come to consider how the parameters interact. In other classrooms, students share the 
data they have created to generate a master data table that includes information from all groups' designs or that tallies the results of shared tests. Perhaps most importantly, the sharing of testing and data permits a period of shared reflection in which students can look across the designs of all groups and distill principles about what variables might influence how the technologies behave.

After students have designed their tomb illumination system and have scored it on the cost and intensity rubric to create a total score, they engage in a class discussion. Each group describes its lighting system to the class - what materials they used and how. The group explains which parts of the system its members believe worked well and which did not. The public conversations allow the teacher to ask students to reflect upon relationships like distance and intensity and the number of mirrors and their placement, to open a discussion that could inform the redesign of their technology. Because the entire class is privy to the conversation, all members and groups can draw on what they learn. Such knowledge informs students' next design and makes them smarter about light and optics.

\section{Ensure engineering is an iterative process}

Throughout history, humans have improved technologies to better suit their needs. Many first designs often do not function or function well. Fortunately, students (and engineers) look forward to redesigning them to make them better. Engineering challenges should include time for students to iterate and create another version of their design. Such redesign can be informed by students, the teacher, or the class asking what worked well, what could be improved, and then permitting them to design, create, and test another version. Comparing the performance of the new version with the original one allows students to see if their changes improved the design. If given the chance, most students welcome the opportunity to redesign and redesign.

After sharing their data with the class, groups doing the optical engineering challenge make tweaks to their design and recalculate their cost and intensity scores. They share these new data again with the class - sometimes on the same data table so they can assess whether the changes positively impacted the outcome. By engaging in these authentic practices of engineering, students build affiliation and academic identity.

\section{Evidence for effectiveness}

There is emerging evidence of the effectiveness of the learning theory and curriculum design supporting the learning opportunities described in this chapter. In the optical engineering example described previously, we identified how, by providing avenues for multiple solutions and mutual learning, students were able to apply creativity to solve problems. Across the five steps of the iterative engineering design process, students engaged in a number of discourse practices supporting engineering and science learning. The students' abilities to engage 
in practices of engineering entailed not only taking actions, but also listening, speaking, drawing, writing, and interpreting multiple forms of communication. This is an important part of the learning approach. Our research about the value of the engineering design process and engagement in engineering practices, draws from discourse analysis - the study of language-in-use. We applied discourse analysis across a set of educational research studies to make sense of the students' emerging communicative competence in these technical discourses (Hymes, 1972; Wallat \& Piazza, 1988). Discourse analysis refers to the study of language-in-use in some setting (Bloome, Carter, Christian, Otto, \& ShuartFaris, 2005; Cazden, 2001; Green \& Castanheira, 2012). In the three studies described below we considered the ways that everyday life in the classrooms shaped and was shaped by the discourse processes. Discourse includes verbal exchanges, contextualization such as gesture, written texts, signs and symbols, and other semiotic resources (Gumperz, 2001). Importantly, the moment-tomoment interactions that create everyday life through discourse are situated in social and cultural practices of a relevant speech community and thus over-time analysis is required to understand the meaning of instances of talk and action (Kelly \& Green, 2019). These studies were all conducted in classrooms using EiE engineering units; thus, they follow the same curricular design principles as those described in the optical engineering unit.

The engagement of students in engineering practices involves not only carefully designed and tested curricula, but also informed instructional practices. In the first study, Cunningham and Kelly (2017b), we examined how a 4th-grade teacher and her students constructed a set of classroom norms and expectations for "talking" engineering and science in an aerospace engineering unit. In this study, the analysis of the classroom discourse demonstrated a set of teacher moves that support student engagement in engineering practices. For example, the teacher posed questions, revoiced student responses, and modeled ways of thinking about data analyses. In this way, the classroom community developed common foci around science concepts and engineering processes and held each other accountable to common standards of quality in engineering work. This common knowledge provided a basis for evaluation of the engineering designs and a means for students to learn to improve design from sharing of data and results. The development of students' competence in these discourse practices was supported by the teachers' uses of metadiscourse - talk about the ways they were talking about engineering and themselves as engineers.

In this first study (Cunningham \& Kelly, 2017b), the teacher's discourse moves supported a learning community. In another study of elementary engineering, the prominence of students' written engineering notebooks was evident. Hertel, Cunningham, and Kelly (2017) took an ethnographic perspective to study the role of the engineering notebook in organizing, facilitating, and documenting the work of finding solutions to engineering design challenges across four different EiE units (package, electrical, geotechnical, and environmental engineering). In this study, the teachers provided the students with an engineering 
notebook - a set of bound worksheets from the curriculum designed to scaffold the students' work and reflections about the engineering challenge. The notebooks included schematics, data tables, rubrics, and spaces for drawing designs. Such supports allowed for common ways of engaging in productive discussion related to the disciplinary practices such as predicting, justifying decisions, and communicating solutions. In this manner, the notebooks allowed for students to creatively solve problems, and also provided common means for sharing and communicating results. The study documented how the notebooks scaffolded student activity and supported engagement in the practices of engineering. Thus, the communicative competence of the students was facilitated by the written and spoken discourse used in conjunction to support engaging in engineering practices.

The framing of the disciplinary knowledge through metadiscourse and the uses of written discourse in engineering notebooks both supported student communicative competence as they appropriated disciplinary knowledge and fostered identity work - the ways that the students use discourse to come to view themselves. Kelly, Cunningham, and Ricketts (2017) applied a sociolinguistic perspective to show how engagement in engineering builds the potential for students to see themselves differently as learners and students of aerospace and materials engineering. In the two units examined, the teachers and students engaged in engineering practices and subsequently called their actions "engineering," leading to development of student affiliation and identity with engineering. This was accomplished through the talk action of engaging in engineering practices, and publicly recognizing and acknowledging such engagement as engineering. Much like the Lighten Up unit described in this chapter, the two units provided multiple opportunities to use the engineering design process to propose unique and creative solutions to ill-structured problems. The students not only referred to their work as engineering and themselves as engineers, they also envisioned future work and possibilities for engineering in their lives. In these and other engineering units, the identity work was the result of talk about the purposeful activities of the classrooms.

\section{Discussion}

The curricular design features of and the enacted discourse practices of the classrooms described in this paper demonstrate ways that children can be supported to develop creativity, problem solving, and communicative competence. Across the curricular units and the examples provided in this chapter, a number of strategies supported this development. We review three ways that the curriculum and classroom discourse work together to support student learning: (a) engaging students in purposeful activity, (b) constructing knowledge to support solutions with evidence, and (c) providing a social basis for dialogue around the evaluation of solutions. These three ways of supporting learning build on and develop communicative competence and support reasoning. 
First, central to developing creative problem solving is engaging students in purposeful activity. The EiE curricular units are composed of four lessons that provide a thematic approach to the study of engineering that includes providing a context, developing awareness about the disciplines of engineering, learning science relevant to the design challenge, and completing the engineering design challenge. This orientation has the benefit of building coherent lessons across the unit that provide motivation, encourage multiple solutions, and include multiple iterations of design, testing, and redesign. Across the four lessons constituting the engineering unit, the students reason through problems using the engineering design process. This fosters the development of reasoning skills related to the disciplinary knowledge (in the hieroglyphics example, properties of light) and engineering practices (such as improving through iteration). The design solutions depend on knowing about light propagation, reflection, and intensity, and only through reasoning through the multiple angles of incidence and reflection are the student groups able to illuminate the vulture images. Similarly, they need to learn from iterative design (their own group's and that of other student groups) to improve over time, thus reasoning through the engineering entailed in such optimization.

Second, the students' activities are goal-directed and aligned with the learning goals. Building a learning context for solving problems needs to include a number of important dimensions. In the engineering units, the students' problem solving was informed by relevant knowledge and evidence constructed in and through the classroom activities. To support this work, the curricular units built in scaffolding processes. Throughout the lessons, the engineering design process was introduced, evoked, employed, and reviewed to organize and support the student work. This design process served as a framework to draw in relevant knowledge to inform decisions made in the classrooms about the science, engineering, and processes for decision making. Such decision making depended on the use and evaluation of relevant evidence. Evidence in engineering design can take multiple forms, and often spans different modes of communication. Students use evidence to make meaning across modes in engineering. Such modes include using everyday discourse to communicate ideas; evoking science concepts to provide the basis for a decision; illustrating a process through written, symbolic, or gestural communication; or employing the materiality of the engineering design itself as an instantiation of knowledge. In this way, the articulation and interpretation of evidence supports the development of communicative competence (Hymes, 1972; Mishler, 1972). The students come to learn how to employ the discourse features of technical knowledge (reflection of light, properties of materials) and to do so in ways that are consistent with the local speech community (adhering to the norms for data sharing and discussion). In the examples from the designing lighting systems unit, the students were asked to consider how to create solutions through deliberative processes in small groups and whole class conversations.

Third, engaging in purposeful activity to solve problems with evidence advances student thinking about the science and engineering involved in the 
lessons. This third way that student learning was supported concerns the basis for dialogue around the evaluation of solutions. Each of the engineering design challenges provided criteria and constraints, structured activity to support multiple solutions, and engaged the students in an iterative process. These activities get students actively involved in constructing knowledge. But this is not enough. In addition to constructing knowledge claims and proposing solutions, the engineering designs need to be tested, evaluated against criteria, refined, redesigned, and rebuilt. Discourse around the assessment of the knowledge and solutions is important to assess the merits of different proposed designs and compare across designs to learn from differences. Thus, the organization of the curricular units and associated classrooms discourse provide a social basis for dialogue around the evaluation of solutions. Dialogues of this sort expand the students' communicative competence beyond just knowing concepts, to using concepts, inventing solutions, and saliently engaging in the discourse of evaluating their own and others' work. This social basis for decision making within and across student groups, and in the whole class, makes participating and learning a collective endeavor. Thus, reasoning is situated in social processes and the local cultural practices of the relevant speech community (the classroom members). The epistemic agent in such cases is the collective - individual reasoning and contributions may be valued, but become candidates for knowledge through the discursive work of classroom members in the varying social configurations of the activities.

In the illustrative examples we provide, support for creativity, problem solving, and communicative competence are interconnected. We offer examples of how allowing for multiple solutions (while adhering to criteria and constraints) encouraged creative design solutions. There are multiple ways to solve the posed problem. By opening up the problem space, and allowing creative solutions, students are situated in social contexts where decisions about engineering designs need to be adjudicated with evidence. By holding students accountable to the criteria and constraints and to each other, the discussions around problem solving become opportunities to employ discourse processes. Because decisions needed to be made with evidence through deliberation, the activities foster communicative competence among the participating students.

\section{References}

Bloome, D., Carter, S., Christian, B., Otto, S., \& Shuart-Faris, N. (2005). Discourse analysis and the study of classroom language and literacy events: A microethnographic approach. Mahwah, $\mathrm{NJ}$ : Lawrence Erlbaum.

Bucciarelli, L. L. (1994). Designing engineers. Cambridge, MA: MIT Press.

Cazden, C. (2001). Classroom discourse: The language of teaching and learning (2nd ed.). Portsmouth, NH: Heinemann.

Cunningham, C. M. (2018). Engineering in elementary STEM education: Curriculum design, instruction, learning, and assessment. New York: Teacher College Press. 
Cunningham, C. M., \& Carlsen, W. S. (2014). Precollege engineering education. In N. Lederman (Ed.), Handbook of research on science education (pp. 747-758). Mahwah, NJ: Lawrence Erlbaum.

Cunningham, C. M., \& Kelly, G. J. (2017a). Epistemic practices of engineering for education. Science Education, 101(3), 486-505.

Cunningham, C. M., \& Kelly, G. J. (2017b). Framing engineering practices in elementary school classrooms. International Journal of Engineering Education, 33(1B), 295-307.

Cunningham, C. M., \& Lachapelle, C. P. (2014). Designing engineering experiences to engage all students. In S. Purzer, J. Strobel, \& M. Cardella (Eds.), Engineering in pre-college settings: Synthesizing research, policy, and practices (pp. 117-142). Lafayette, IN: Purdue University Press.

Engineering is Elementary. (2011a). Lighten up: Designing lighting systems. Boston, MA: Museum of Science, Boston.

Engineering is Elementary. (2011b). Omar's time to shine. Boston, MA: Museum of Science.

Green, J. \& Castanheira, M. L. (2012). Exploring classroom life and student learning: An interactional ethnographic approach. In B. Kaur (Ed.), Understanding teaching and learning: Classroom research revisited (pp. 53-65). Rotterdam, NL: Sense.

Gumperz, J. J. (2001). Interactional sociolinguistics: A personal perspective. In D. Schiffrin, D. Tannen, \& H. E. Hamilton (Eds.), Handbook of discourse analysis (pp. 215-228). Malden, MA: Blackwell.

Hertel, J. D., Cunningham, C. M., \& Kelly, G. J. (2017). The roles of engineering notebooks in shaping elementary engineering student discourse and practice. International Journal of Science Education, 39, 1194-1217.

Hmelo-Silver, C. E. (2004). Problem-based learning: What and how do students learn? Educational Psychology Review, 16, 235-266.

Hutchins, E. (1995). Cognition in the wild. Cambridge, MA: MIT Press.

Hymes, D. (1972). On communicative competence. In J. Pride \& J. Holmes (Eds.), Sociolinguistics: Selected readings (pp. 269-293). Harmondsworth, G. B.: Penguin.

Johnson,A. (2009). Hitting the brakes: Engineering design and the production of knowledge. Durham, NC: Duke University Press.

Kelly, G. J. (2016). Methodological considerations for the study of epistemic cognition in practice. In J. A. Greene, W.A. Sandoval, \& I. Braten (Eds.) Handbook of epistemic cognition (pp. 393-408). New York: Routledge.

Kelly, G. J., Cunningham, C. M., \& Ricketts, A. (2017). Engaging in identity work through engineering practices in elementary classrooms. Linguistics \& Education, 39, 48-59.

Kelly, G. J., \& Green, J. (Eds.). (2019). Theory and methods for sociocultural research in science and engineering education. New York: Routledge.

Kelly, G. J., McDonald, S., \& Wickman, P. O., (2012). Science learning and epistemology. In K. Tobin, B. Fraser, \& C. McRobbie (Eds.), Second international handbook of science education (pp. 281-291). Dordrecht, The Netherlands: Springer.

Kozulin, A. (2003). Psychological tools and mediated learning. In A. Kozulin, B. Gindis, V. S. Ageyev, \& S. M. Miller (Eds.), Vygotsky's educational theory in cultural context (pp. 15-38). Cambridge, UK: Cambridge University Press.

Lachapelle, C. P., \& Cunningham, C. M. (2014). Engineering in elementary schools. In S. Purzer, J. Strobel, \& M. Cardella (Eds.), Engineering in pre-college settings: Synthesizing research, policy, and practices (pp. 61-88). Lafayette, IN: Purdue University Press.

Mishler, E. (1972). Implications of teacher strategies for language and cognition: Observations in first-grade classrooms. In C. B. Cazden, V. P. John, \& D. Hymes, (Eds.), Functions of language in the classroom (pp. 267-298). New York:Teachers College Press. 
NGSS Lead States. (2013). Next Generation Science Standards: For states, by states. Washington, DC: The National Academies Press.

Petroski, H. (2006). Success through failure: The paradox of design. Princeton, NJ: Princeton University Press.

Reveles, J. M., Kelly, G. J., \& Durán, R. P. (2007). A sociocultural perspective on mediated activity in third grade science. Cultural Studies in Science Education, 1, 467-495.

Vincenti, W. G. (1990). What engineers know and how they know it. Baltimore, MD: Johns Hopkins University Press.

Vygotsky, L. (1978). Mind in society: The development of higher psychological processes. Cambridge, MA: Harvard University Press.

Wallat, C., \& Piazza, C. (1988). The classroom and beyond: Issues in the analysis of multiple studies of communicative competence. In J. L. Green \& J. O. Harker (Eds.), Multiple perspective analyses of classroom discourse (pp. 309-341). Norwood, NJ: Ablex. 